\title{
Assessing Present and Future Ozone Hazards to Natural Forests in the Alpine Area - Comparison of a Wide Scale Mapping Technique with Local Passive Sampler Measurements
}

\author{
Angelo Finco, Stefano Oliveri, Giacomo Gerosa, \\ Wilfried Winiwarter, Johann Züger and \\ Ernst Gebetsroither
}

Additional information is available at the end of the chapter

http://dx.doi.org/10.5772/56280

\section{Introduction}

\subsection{Ozone and vegetation}

Ozone is considered as one of the most phytotoxic pollutant for vegetation [1]. Ozone penetrates the leaves through the stomata and it dissolves in the water film enveloping the cellular walls of the substomatal cavity. The reaction of ozone and water releases oxidative radicals like hydrogen peroxide, superoxide and similar compounds, which are known as ROS (Reactive Oxygen Species). The ROS are responsible for oxidative stress causing biological injuries. The injuries begin with the membranes disruption through the peroxidation of the membrane lipids, and go on with the oxidation of the reduced groups of biomolecules, particularly enzymes with a subsequent change of the biochemical pathways. Once ROS enter the chloroplasts, the chlorophylls of the photosystem reaction centers are damaged leading to a general reduction of the plant growth and productivity $[2,3,4]$.

The microscopic effects can appear as visible injuries at leaf level, such as chlorosis, bronzing and necrosis, as increased transparency at crown level, as a reduced root growth, and as a general increased susceptivity to both biotical and abiotical stresses [5]. Nevertheless in many cases ozone damages may not show any visible symptoms but only physiological changes which can however lead to a productivity decrease [6,7]. 
At ecosystem level this stressor can cause slow structural changes to the plant community composition, favoring more resistant species[8]; in fact, different level of plant sensitivity to ozone were observed. Functional changes at ecosystem level can affect ecosystem services reducing carbon storage capability, increasing water loss and reducing the forest capability of stabilizing mountain slopes.

No direct ozone sources, both anthropogenic and natural, exist, ozone in fact is a secondary pollutant which is produced by photochemical reactions between nitrogen oxides $\left(\mathrm{NO}_{\mathrm{x}}\right)$ and volatile organic compounds (VOC). These reactions are burst by UV radiation and hence the ozone production is obviously greater in summer and at higher elevation, provided not limiting air concentrations of the precursors (i.e. $\mathrm{NO}_{\mathrm{x}}$ and $\mathrm{VOC}$ ). $\mathrm{NO}_{\mathrm{x}}$ mostly come from high temperature combustions both from vehicles and energy production plants, while VOC can be emitted also by vegetation itself (isoprene and terpenes) as well as by the same anthropogenic sources of $\mathrm{NO}_{x}$ when the combustion is not perfectly balanced. In mountain regions the breeze cycle generates pollution transport from valley bottom or planes, where typically precursor sources are located, to higher elevation forested areas. As a consequence mountain forests can experience higher ozone concentrations than the valley floor. In the southern side of the Alps these processes are enhanced because of the higher solar radiation and temperature, the higher elevation and the great number of precursor sources in the Po valley; furthermore the enclosed morphological configuration of the Po basin can contribute to trap the ozone precursors and to push them towards the mountain tops.

\subsection{Ozone hazard assessment an EU legislation}

Ozone hazard was widely studied during last decades. The United Nations Economic Commission for Europe (UN/ECE) gave birth in 1979 to the Convention on Long-range Transboundary Air Pollution (LRTAP). The Convention is composed by more 50 states from Europe, Asia and North-America and several protocols were signed to identify specific measures to limit their emissions of pollutants and gradually reduce pollution levels and also long-range transboundary air pollution. In particular, the Gothenburg protocol (1999) fixed the critical levels of ozone for vegetation with target values for the following years. A following EU directive (2002/03) acknowledged the Gothenburg protocol, which already explained how to assess the ozone hazard, introducing the AOT40 (Accumulated Ozone Exposure over a threshold of $40 \mathrm{ppb}$ ) index. The AOT40 is defined as:

$$
\text { AOT40 }:=\sum_{\substack{\left[\mathrm{O}_{3}\right]_{i}>40 \mathrm{ppb} \\ \text { RadGlob }>50 \mathrm{~W} / \mathrm{m}^{2}}}\left(\left[\mathrm{O}_{3}\right]_{i}-40\right) \cdot \Delta t
$$

that is the AOT40 is calculated as the sum of the concentrations of ozone (when they are above $40 \mathrm{ppb}$ ) minus the threshold of $40 \mathrm{ppb}$ multiplied by the measuring time which is usually one hour. This sum is calculated only during daylight hours in order simulate the stomatal behavior of vegetation. Even though this index reflects the concept of exposure, the choice of calculating it only during daylight hours was an attempt to mime the concept of dose, that is the amount of ozone taken up by plants through stomata, whose opening is regulated by sun light (but also by other environmental factors). 
The critical levels set by EU for vegetation is $18000 \mu \mathrm{g} \mathrm{m} \mathrm{m}^{-3} \mathrm{~h}$ over a period of six months, from $1^{\text {st }}$ April to $30^{\text {th }}$ September. This critical level can be expressed also in terms of $\mathrm{ppb} \mathrm{h}$, and its value is $9000 \mathrm{ppb}$ h. UN/ECE, after the signing of the Gothenburg protocol, enhanced and promoted studies about ozone effects on vegetation and suggested a new critical level for forest (5000 ppb h during the growing season).

The choice of this new critical level was based on some experiments where seedlings of beech and birch (two sensitive species) where exposed to different levels of ozone concentrations, and hence different levels of AOT40 were measured; after the growing season a biomass reduction of the plants exposed to ozone was observed and plotted versus the corresponding values of the AOT40 (Figure 1). The critical level of $5000 \mathrm{ppb}$ h corresponds to a potential biomass reduction of $5 \%$ (intercept of the two dashed lines). Knowing the AOT40 to which an ecosystem was exposed (for example $20.000 \mathrm{ppb}$, that is equal to $20 \mathrm{ppm} \mathrm{h}$ ), the potential biomass reduction can be estimated following the blue arrow first and then the red one, which leads to a $16 \%$ potential biomass reduction.

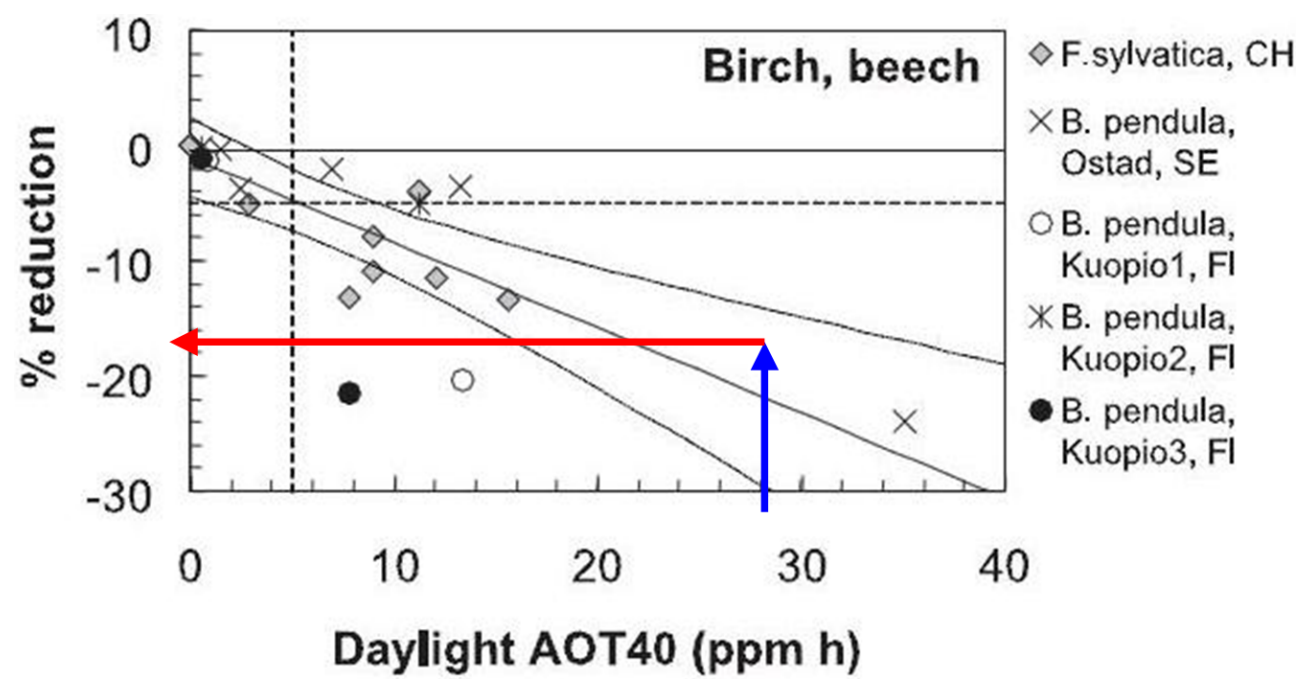

Figure 1. Modified from [9].The relationship between percentage reduction in biomass and AOT40, on an annual basis, for the deciduous, sensitive tree species category, represented by beech and birch. The blue and red line are used to estimate the biomass reduction as a function of the AOT 40 value.

The EU directive gives recommendations to the member state about how to measure ozone and how to calculate AOT40, but, since the monitoring networks are mostly dedicated to estimate the risk for the population rather than vegetation, ozone data in mountain regions are not so often available, leading to a not proper evaluation of the ozone hazard for forests. Three main options are available to avoid this lack: mobile laboratory, passive samplers and modeling predictions. 
Mobile laboratories are vans which are equipped with a small meteorological station and automatic instrumentation to measure continuously the pollutant concentrations (Figure 2). However, due to their high electric power consumption, mobile labs are seldom suitable for monitoring in forest remote areas.

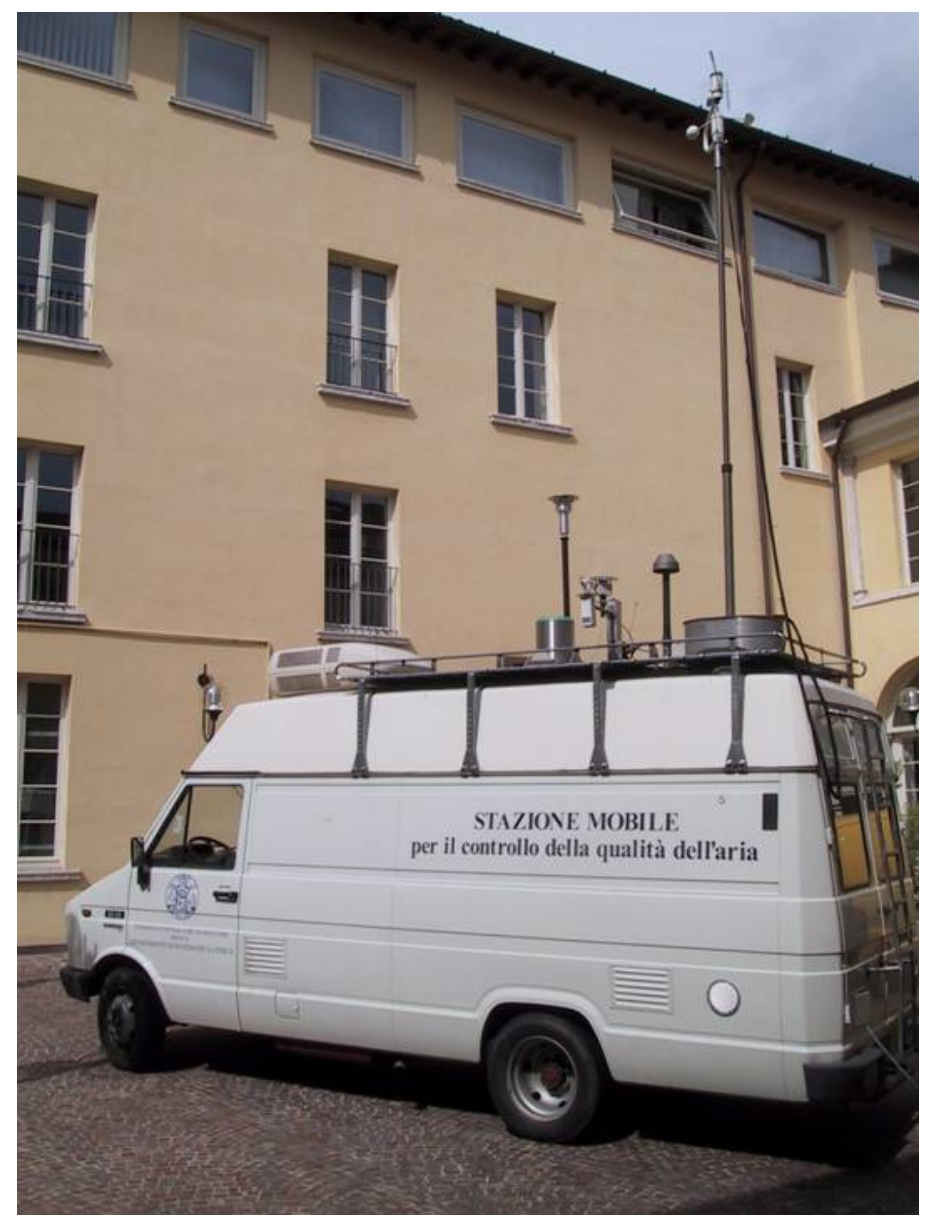

Figure 2. The mobile laboratory employed in the MANFRED project

Passive samplers, on the contrary, do not require electricity since they are tubes which are filled with a substance which reacts to ozone (Figure 3). Passive samplers must be exposed to ambient air, typically for one week, and then collected and sent to chemical lab to obtain the average ozone concentration of the exposure period. Passive samplers are a valuable option for measurements in remote area even tough the time resolution of these devices is their main disadvantage. 


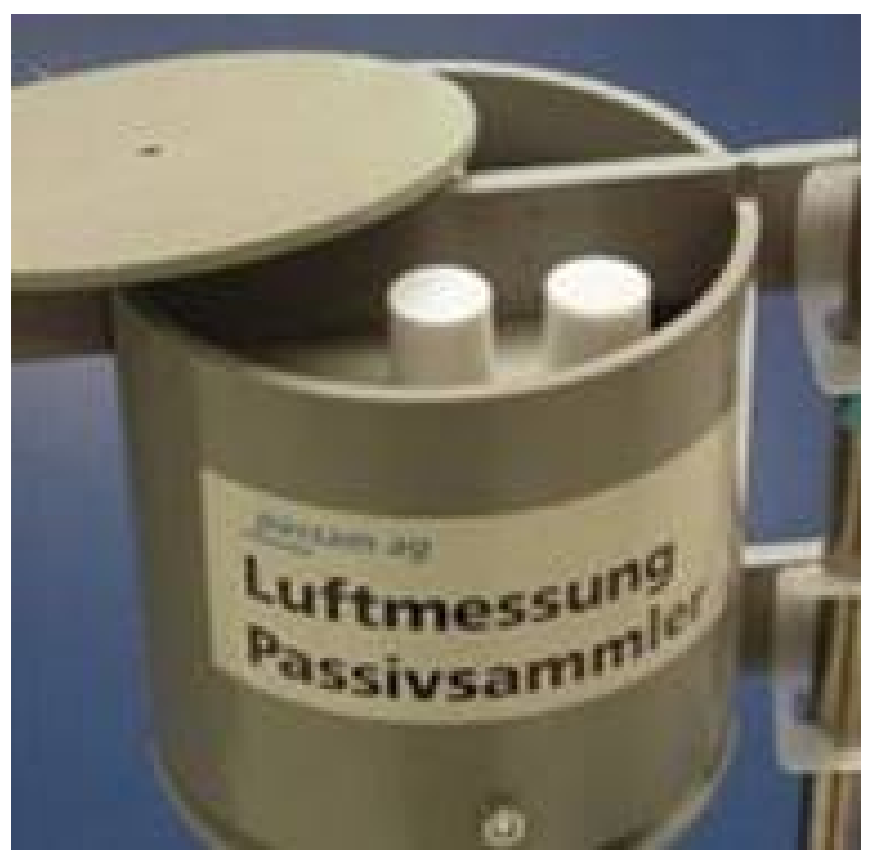

Figure 3. Ozone passive samplers

Ozone concentrations modeling is another valuable option which allows to map ozone hazard at wide scale, in some way avoiding the technical, economical and logistical constraints involved in the use of the instrumentation. However the goodness of the modeling outputs is strictly correlated to the quality of the input data supplied. This could be an important limitation as well as the fact that the model predictions should be validated with direct measurements in the studied area.

In this chapter the modeling of ozone hazard and the related AOT40 maps at Alpine scale will be showed and compared with direct measurements performed at a finer scale in a selected case study area. Finally an attempt of estimating the future ozone hazard in the Alpine area will be showed too.

\section{The present ozone risk in the Alps and a case study in depth analysis}

\subsection{Mapping AOT40 at Alpine scale level}

\subsubsection{Model description}

During the years 1990 - 1994 the Foresight \& Policy Development Department of AIT developed a model to generate hourly ozone concentration maps using ozone monitoring data, 
considering the influence of complex terrain on diurnal ozone variation within mountain areas. The model was designed and tested within the Geographic Information System (GIS) ARC/ INFO. Validity tests showed that the spatio-temporal dynamics of ground level ozone concentrations were calculated with high accuracy and spatial resolution. In 1994 the model was rewritten and included into the ozone monitoring network visualization interface at the Federal Environment Agency Austria (www.ubavie.gv.at).

The idea of the interpolation approach is to make use of the well known elevation dependence of ozone to calculate the overall spatial trend and to include monitoring data to consider seasonal and local influences. The approach needs a digital elevation model of the study area and a monitoring network.

The model is divided into several steps:

1. The core of the interpolation model is based on a function that reflects the dependence of ozone concentration on relative elevation and daytime in mountain regions.

2. The function generates daytime-specific standard ozone/elevation curves showing the increase of ozone concentration with increasing elevation.

3. Hourly ozone concentration measurements are used to include seasonal and day-specific influence to the average ozone concentration by fitting the standard ozone/elevation curves.

4. The day-specific curves and a digital elevation model are used to generate day-specific ozone concentration surfaces per daytime.

5. The deviations of the observed from the calculated ozone concentrations reflect the local influences at the monitoring stations. The interpolation of those deviations leads to a deviation surface.

6. The combination of the (hourly) day-specific ozone concentration surface with the hourly deviation surface leads to actual daytime- and day-specific ozone distribution maps of the study area considering the local influences.

The relative elevation is the vertical distance between the valley bottom and any location within the mountains. It is calculate out of a digital elevation model (DEM) where the valley bottom was assumed as the lowest absolute elevation within a distance of $5 \mathrm{~km}$ around every DEM - grid point $[10,11]$.

The diurnal variation of ozone concentration depending on daytime and elevation is described by an analytical function. It was approximated by analyzing scatter plots of hourly ozone concentrations against relative elevation of the monitoring sites [10, 11].

Eq. 2 shows the basic function to model standard ozone concentrations:

$$
O_{s t d}\left(h_{r e l}, t\right)=\left(a_{1}+a_{2} \cdot e^{-\left(t-a_{3}\right)^{2} a_{4}}\right) \cdot \ln \left(\frac{b_{5} \cdot h_{r e l}}{100}+b_{1}+b_{2} \cdot e^{-\left(t-b_{3}\right)^{2} b_{4}}\right)-\frac{c_{1}}{1-\left(t-c_{2}\right)} \cdot \frac{h_{r e l}}{c_{3}}
$$


with

$\mathrm{O}_{\text {std }}=$ standard-ozone-concentration,

$\mathrm{h}_{\text {rel }}=$ relative height, $\mathrm{t}=$ time of day,

$a_{x}, b_{x}, c_{x}=$ parameters of the function

This function generates a 2-dimensional trend surface of ozone concentration reflecting the dependencies of ozone on elevation and daytime (Figure 4). Slicing the surface parallel to the time-(x)-axis one gets the diurnal variation for any elevation level, slicing the surface parallel to the elevation-(y)-axis one gets ozone/elevation curves for any time of day. These standard ozone/elevation curves show the increase of ozone concentration depending on increasing elevation at a specific time of the day and are the basis to generate daytime-specific ozone concentration.

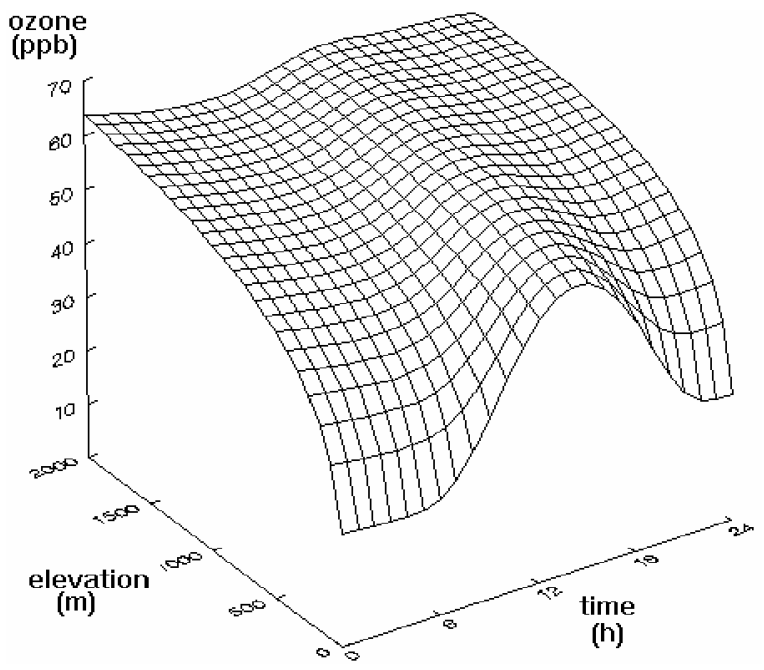

Figure 4. Trend surface of the standard ozone/daytime/elevation function

\subsubsection{Ozone measurement data}

The Ozone monitoring data have been taken from AirBase ${ }^{1}$. This is a public air quality database containing hourly air monitoring information for 35 countries throughout Europe. In total there are more than 2500 surface ozone measurement stations available. Approximately 330 AirBase ozone measurement sites can be found within the Greater Alpine Region, the study Area of the MANFRED project. The data availability for the countries surrounding the Alps (A, CH, D, F, I, FL, SLO) is shown in Figure 5.

$1 \mathrm{http}: / / a c m . e i o n e t . e u r o p a . e u / d a t a b a s e s / a i r b a s e /$ 

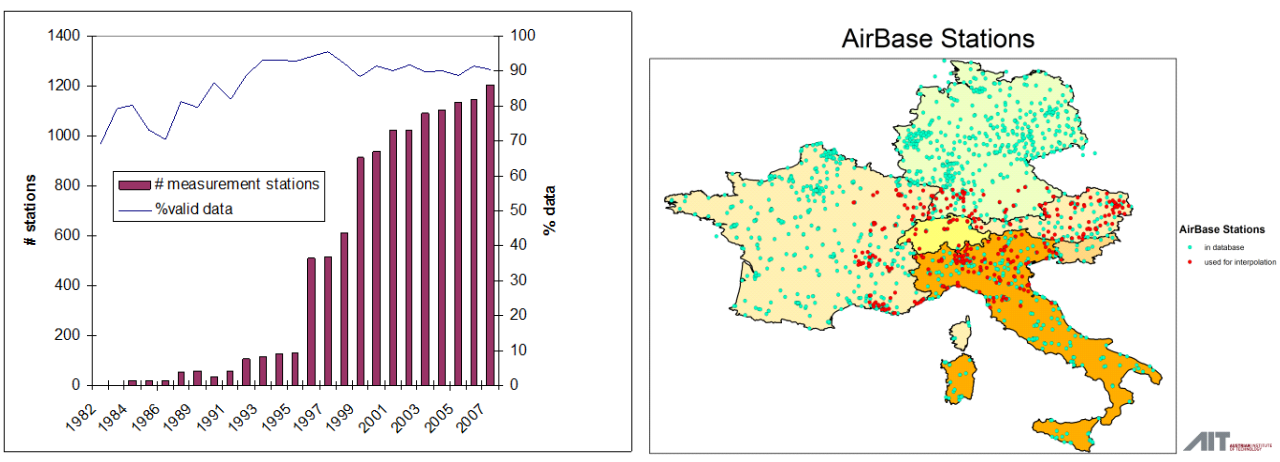

Figure 5. Number of measurement stations and amount of valid data for countries surrounding the Alps (left) and the Geographical coverage in 2007 (right)

\subsubsection{Results for the Greater Alpine Region (GAR)}

Ozone interpolation was done from 2003 to 2007 with 1 hour time and $1 \mathrm{~km}$ spatial resolution resulting in 43824 maps with 1018x668 grid points and app. 400 GB of data. In addition AOT40 maps with $1 \mathrm{~km}$ spatial resolution were calculated for the years 2003 to 2007, which can be seen in Figure 6.

Figure 6 shows that the interannual variability of the AOT40 values is significant (2003 was an extreme year). The $5 \mathrm{yr}$ mean (Figure 6, lower right map) gives an overview about the spatial distribution of the AOT40 values. In general a higher AOT40 value can be expected in the south of the alpine main ridge.

\subsection{Measurements at local scale with passive samplers: The Valle Camonica case study}

Valle Camonica was chosen as a case study area for ozone since this pollutant is a well known problem for the Lombardy region where it is located [12]. Even tough Valle Camonica is one of the biggest forested valley in Lombardy, few information on ozone hazard for forest were available for this valley and some ozone-like foliar symptoms were observed on beech leaves.

In summer 2010 a six month field campaign was performed with passive samplers located in 11 sites throughout all the valley: 10 of them were placed in remote forest areas while the remaining one was placed in Darfo, near the only automatic monitoring station available in Valle Camonica (Regional environmental agency, ARPA). The sites elevation ranged between $300 \mathrm{~m}$ and $1800 \mathrm{~m}$ a.s.l. spatially covering all the forest areas of the valley.

The employed passive samplers were polypropylene tubes with a glass fiber filter dipped in a solution of DPE (1,2-di(4-pyridyl)-ethylene) in acetic acid at the closed end (Passam ag, CH). The ozone diffusing in the tubes reacts stoichiometrically with DPE forming an ozonide which undergoes cleavage and yields an aldehyde. The amount of aldehyde is then determined spectrophotometrically in lab by the MBTH (3-methyl-2-benzothiazolinone hydraze ethylene) 
AOT40 values from interpolated Ozone maps for 2003

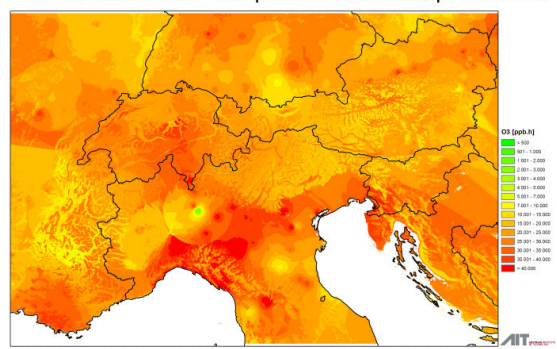

AOT40 values from interpolated Ozone maps for 2005

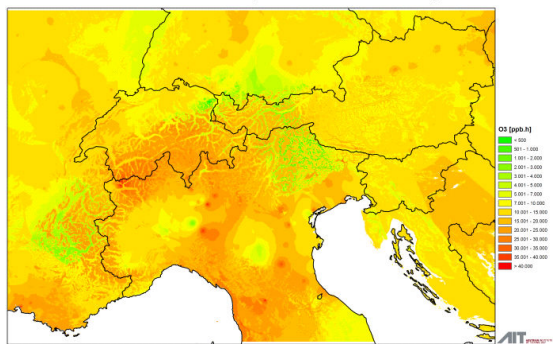

AOT40 values from interpolated Ozone maps for 2007

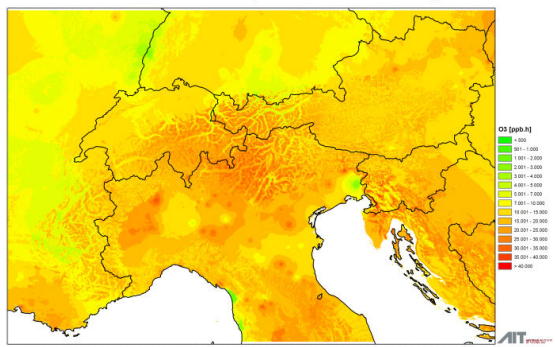

AOT40 values from interpolated Ozone maps for 2004

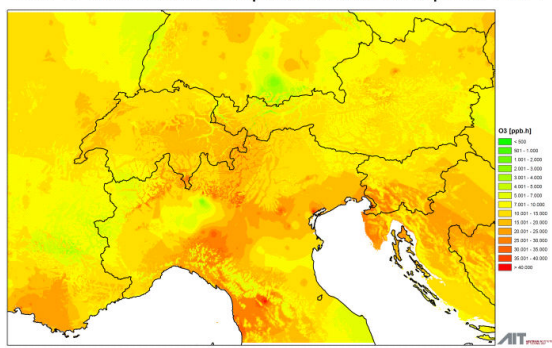

AOT40 values from interpolated Ozone maps for 2006

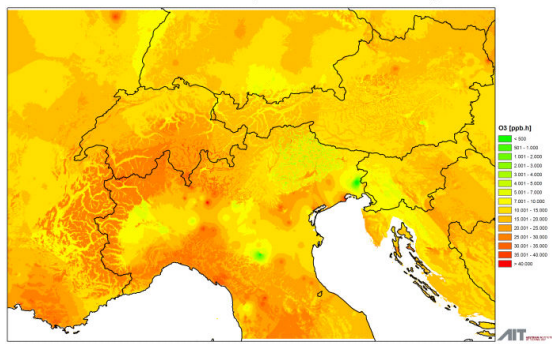

AOT40 values from interpolated Ozone maps $5 y$ mean

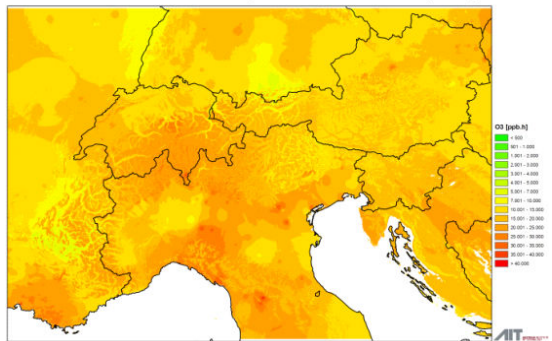

Figure 6. AOT40 maps for 2003 to 2007 and 5 yr mean, derived from interpolated 1-hourly ozone maps

method at $442 \mathrm{~nm}$, giving directly the mass of the captured ozone. The ozone concentration in the air $\left(\mu \mathrm{g} \mathrm{m}^{-3}\right)$ is calculated using the Fick's law, knowing the diffusion coefficient of ozone in the air and the tube geometry.

Two polypropylene tubes were exposed for one week in each site, inside a protective shelter preventing the advective ozone capture due to the wind (Figure 3). The first exposure began at $6^{\text {th }}$ April 2010 and the last one (the $26^{\text {th }}$ one) ended at $6^{\text {th }}$ October 2010.

In order to calculate the AOT40, the collected ozone air concentrations were converted into volumetric ratios ( $\mathrm{ppb}$ ) taking into account the elevation of each site, following the methodology described in [13]. For this purpose temperature and pressure data from meteorological stations in the valley were used. 
In order to calculate the AOT40 it is necessary to estimate hourly ozone concentrations starting from the weekly averages, the only data available from passive sampler measurements. For this sake the Loibl function (Eq. 2) was used. This function models the ozone concentration hour by hour given the relative height of the site, i.e. the difference between the elevation of the site and the elevation of the lowest point within a range of $5 \mathrm{~km}$. The Loibl function has been shifted so that its average was set equal to the passive sampler value (weekly average) and it was also assumed that the daily course of all the days of the exposure period was the same. Further details on this methodology can be found in [14]. The Loibl function capability of predicting the ozone daily course in our case study has been tested by setting up 8 intensive monitoring campaigns in different sites of the valley with a mobile lab equipped with continuous analyzers.

AOT40 was then calculated for each measurement site (Eq. 1) using the hourly ozone concentration obtained from the shifted and replicated Loibl function for all the days of each exposure week. Weekly values of AOT40 were mapped on the Valle Camonica domain using a geostatistical technique known as ordinary kriging [10,11], which requires a model of the spatial data variability estimated from the semivariogram plots.

Further details on this mapping technique can be found in [14]. Then the 26 weekly AOT40 maps were summed to obtain the ozone hazard map for forests in Valle Camonica $\left(6^{\text {th }}\right.$ April $6^{\text {th }}$ October).

\section{Passive sampler vs monitoring station}

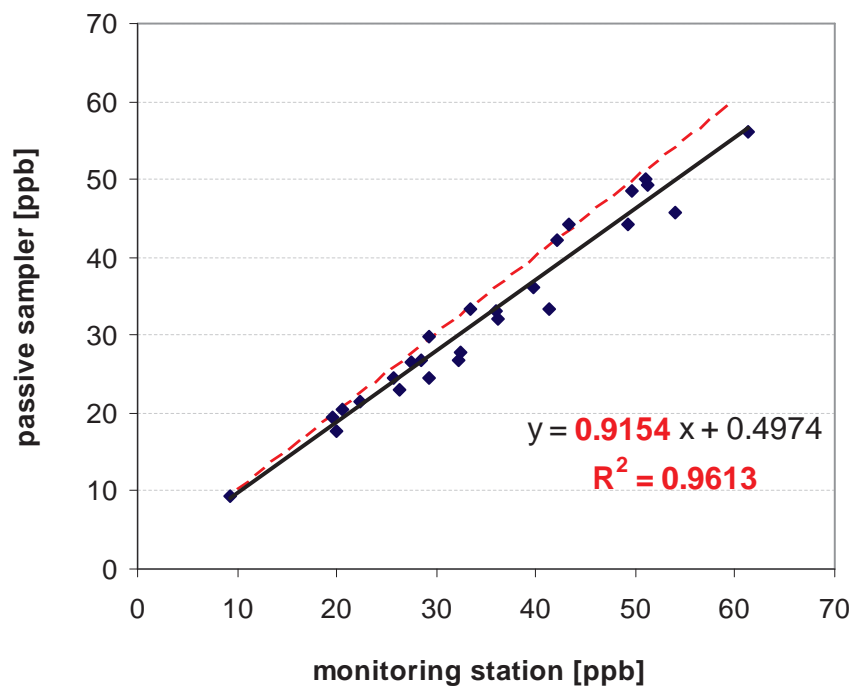

Figure 7. Passive sampler measurements compared with a nearby continuous analyzer 
The performance of the passive sampler was very good as it can be verified from Figure 7 where the passive sampler measurements were compared with the calibrated continuous analyzer ones $\left(R^{2}=0.96\right.$, slope $\left.=0.91\right)$.

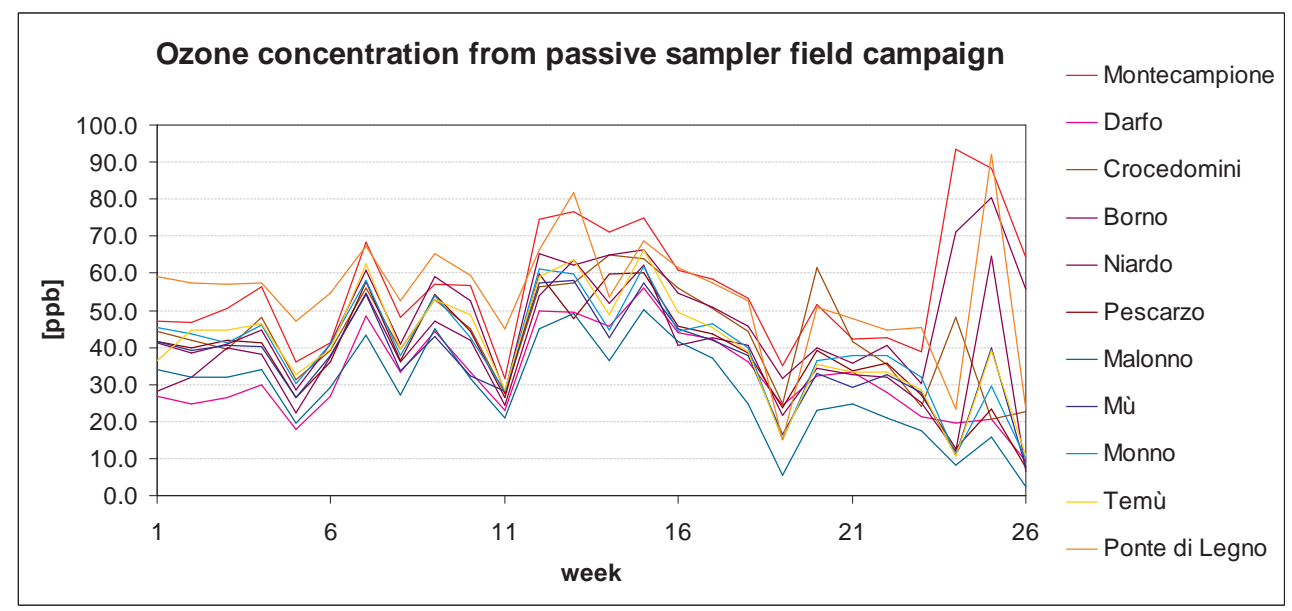

Figure 8. Ozone concentration measurements of all the sites in the measuring period

Figure 8 reports all the measurements of all the sites in the whole measuring period. There is a general increase of the ozone concentrations with increasing elevation. It is also evident a clear variability between one week and the other, which highlights the influence of local meteorology on the ozone production. Finally ozone levels show a seasonal trend which follows the intensity of the solar radiation, with a slight increase until the end of June, a maximum in July and a decrease from August. September values appears anomalous with respect to this general trend and they are likely due to ozone intrusion from the upper troposphere after the autumnal repositioning of the tropopause. In fact these anomalous values were measured mainly in high elevation sites.

Figure 9 shows monthly average maps of ozone concentrations in the studied domain. It can be clearly seen that ozone concentration is low in valley floor and it increases regularly with the elevation reaching the maximum values in the Adamello massif, at the eastern edge of the valley. High concentrations were observed also in the southern part of the valley, namely in the Borno upland and at the Montecampione relief, both above at an elevation of $1000 \mathrm{~m}$ a.s.l.. In June and in July a general increase of the ozone background level was measured with a marked increase in south-eastern part of the domain. In August average concentrations lowered in most of the valley with the exception of Borno and Montecampione areas.

The final map assessing the ozone exposure for forests, i.e. the ozone hazard expressed as AOT40, is showed in Figure 10. With the only exception of the valley floor nearby Malonno, 

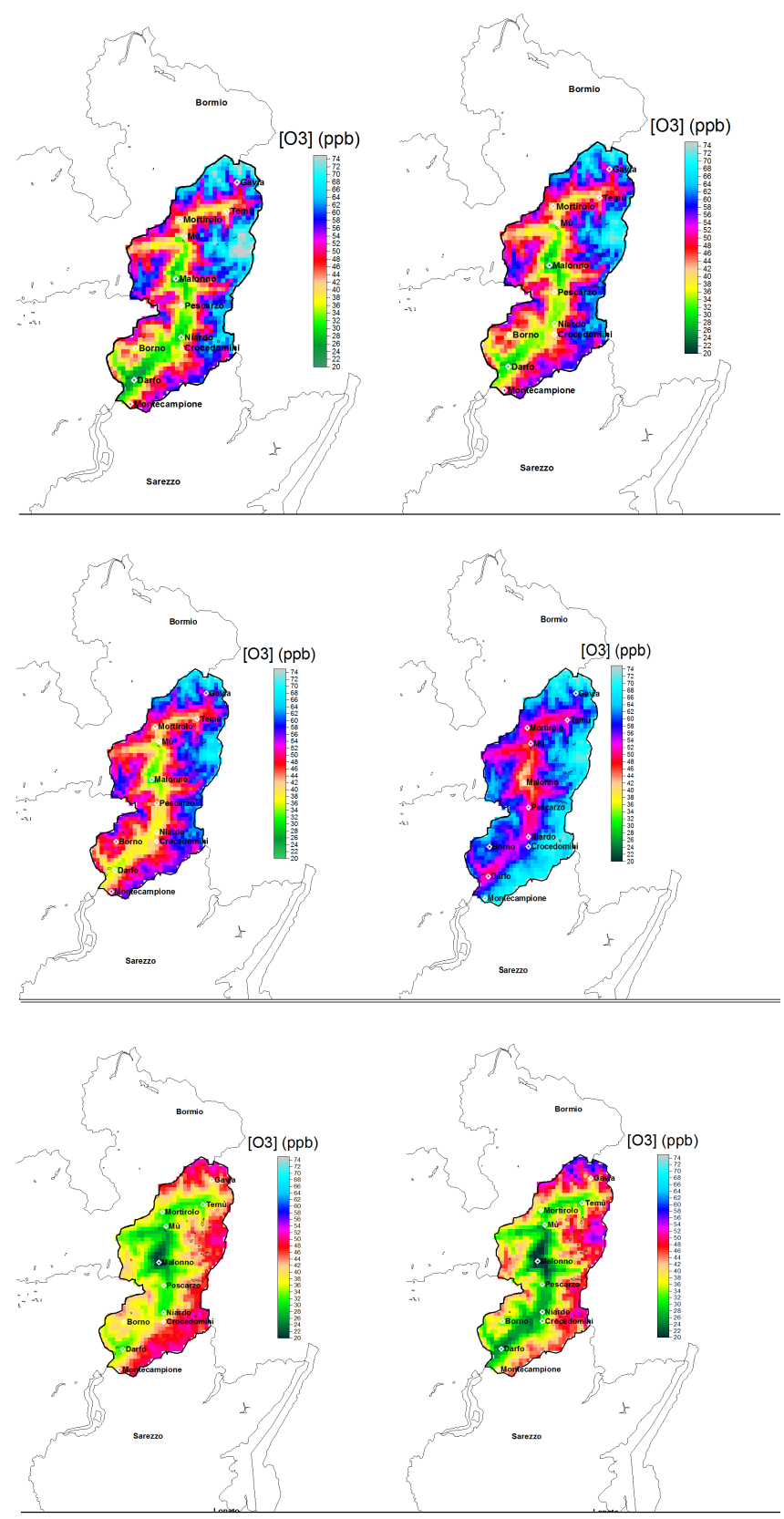

Figure 9. Monthly average maps of ozone concentrations in the Case Study 4 


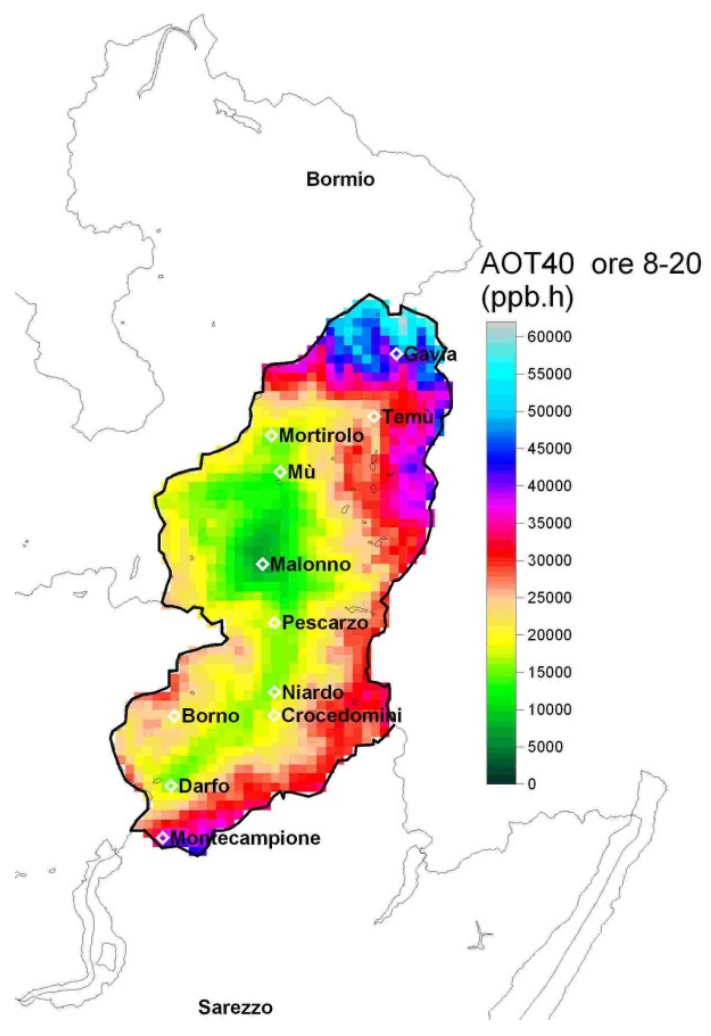

Figure 10. AOT40 map obtained from passive samplers measurements.

all the valley is above the EU critical level for forest ( $9000 \mathrm{ppb}$ h), with exceedances up to 6 times the critical level in the most elevated areas. If the UN/ECE critical level is considered the situation is even worse. This map confirm a potential ozone risk for vegetation in this area.

For a deeper analysis of the risk for the forested area in Valle Camonica refer to the chapter about this case study area.

\subsection{Comparison with the wider scale estimation (the case of Valle Camonica)}

To compare interpolation results, as described in chapter 2.1, with the measurements (chapter 2.2) AIT started to run the ozone interpolation model for Valle Camonica on a very local scale. UNICATT provided ozone data for the period April, $1^{\text {st }} 2010$ to September, $30^{\text {th }} 2010$ from 19 measurement stations in the vicinity of Valle Camonica. In a first step we tried to use the interpolation routine in the same way as we did for the entire alpine region. With that we faced some troubles, mainly depending on the low number of stations. Originally the interpolation routine was developed to work with numerous stations (more than 300 for the Greater Alpine Area) and an acceptable station density. Especially the fact that a maximum of two stations at 
higher altitudes were available was unsatisfactory. As a result of this the algorithm was unable to fit the dependency curve in the top layer and therefore the whole interpolation did not work correctly. We removed the whole day specific fitting part from our routines and did the interpolation just based on the standard elevation/daytime ozone dependency curve. With these modifications the model worked satisfactorily. The following Figure 11 shows the location of measurement stations and AOT40 values from 2010 calculated with the modified interpolation method using 19 local ozone measurement stations. Additionally a comparison of different methods to estimate AOT40 values was done. Because the continuous measurement of ozone in forest areas is difficult often passive samplers are used. The disadvantage of this method is the coarse time resolution, which does not allow calculating AOT40 values directly from measurements. As we found a reasonable correlation between monthly mean ozone and AOT40 values we tested some variants of calculation. The top row in Figure 12 shows results for AOT40 values derived from interpolated 1-hourly ozone maps, calculated with monthly mean/AOT40 correlation function derived from 2010 Valle Camonica data and a function derived from 5-year data of all measurement stations used for the interpolation for the Greater Alpine Region.

DTM, Measurement Stations and Ozone Samplers

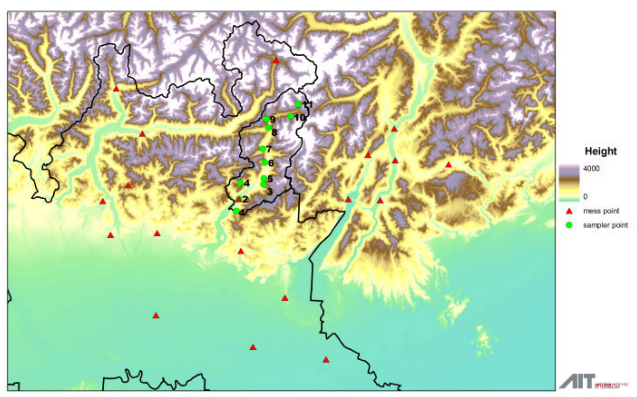

AOT40 - Valle Camonica 2010 Calculated from 1-hourly Ozone Values

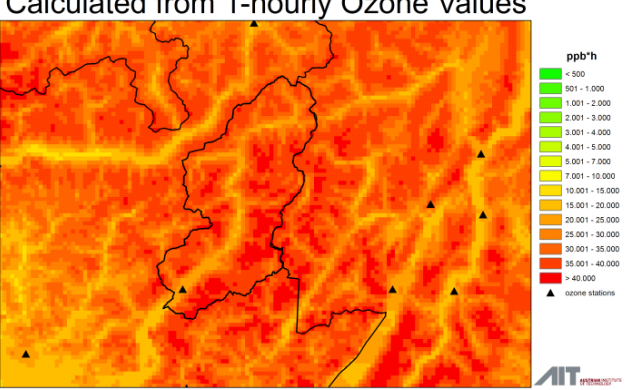

Figure 11. Location of passive samplers and ozone measurement stations (left) and AOT40 map for 2010 derived from 1-hourly Ozone maps produced by local interpolation for Valle Camonica (right)

\section{AOT40 estimations in the Alpine area for the future}

As for the future no hourly based estimations of Ozone concentration are available, we investigated the possibility to calculate the AOT40 values out of monthly means. For all years 2003 to 2007 the 1-hourly maps were aggregated to monthly means and the values at the locations of measurement stations were extracted. As shown in Figure 13 this estimations show a significant correlation between the monthly means and AOT40 values. So we used this approximation for the calculation of the future AOT40 values according to different ozone concentration scenarios. 

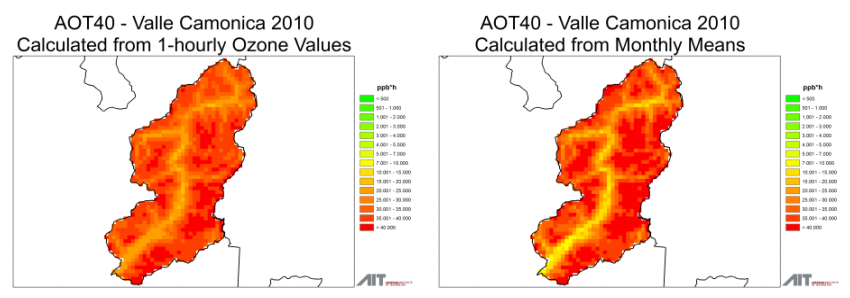

Differences of AOT40 - Valle Camonica 2010
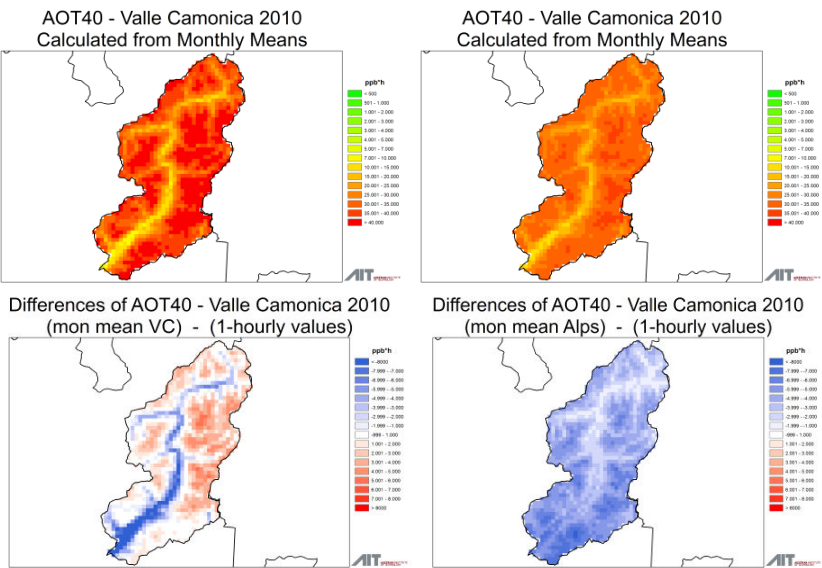

Differences of AOT40 - Valle Camonica 2010 (mon mean Alps) - (1-hourly values)

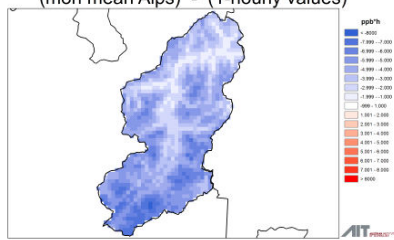

Figure 12. AOT40 maps for Valle Camonica 2010 (top row) derived from 1-hourly Ozone maps (left), correlation monthly mean/AOT40 using 2010 Valle Camonica data (center), using 2003-2007 measurement data from the alpine area (right) and differences compared to AOT40

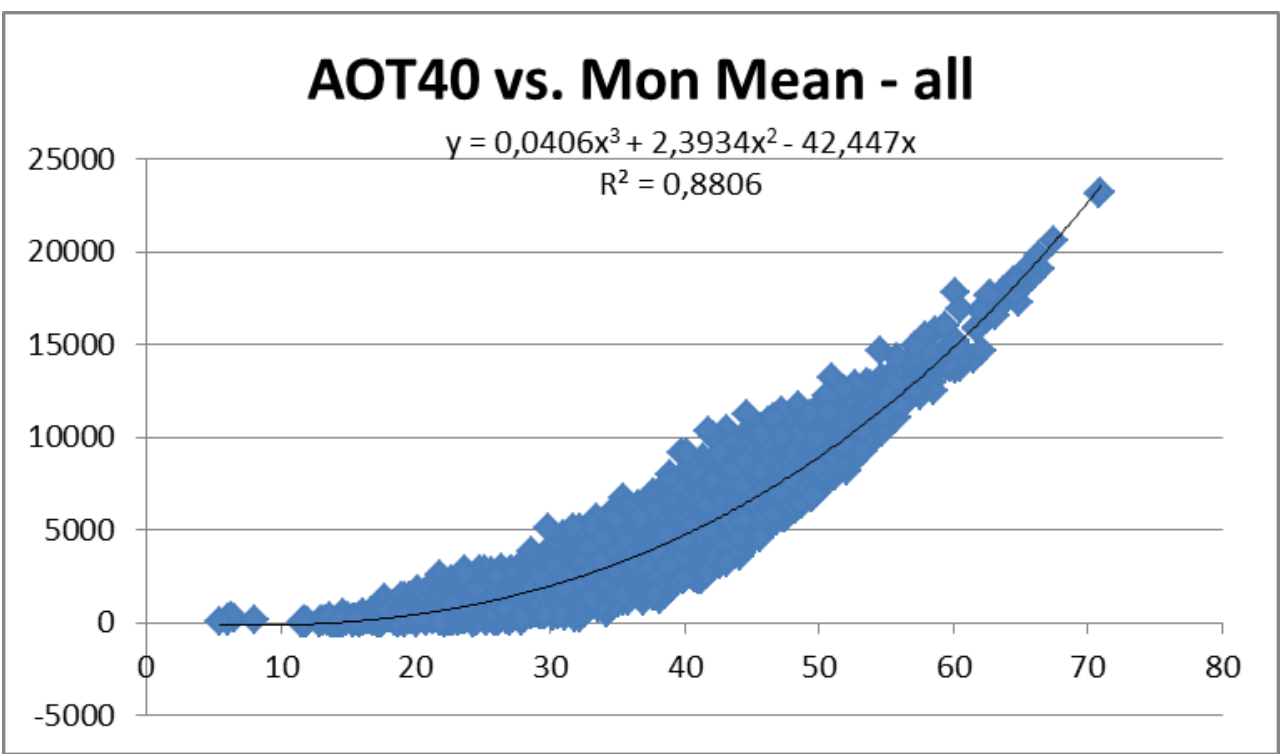

Figure 13. Correlation between monthly mean ozone and AOT40 values for all available stations in the GAR

Two scenarios ${ }^{2}$, originally developed to research future climate conditions and providing ozone concentrations globally until the final decade of this century, were used to estimate the ozone hazard to forests. While application towards air pollution exceeds the scope of climate 
scenarios, at least some guidance on possible future situations may be derived. Scenarios chosen are "RCP2.6", developed as a low climate forcing scenario that minimizes anthropogenic climate impacts, and the "business as usual" scenario "RCP8.5" which extends current trends. They represent very different views of how the world may look in 2100.

The climate change influence on ozone concentrations from the first to the last decade of the $21^{\text {st }}$ century has been obtained from the World Climate Research Program[3] (Figure 14) [15]. This data represent 10 -year means of monthly mean ozone concentrations on a global scale with a spatial resolution of $5^{\circ}$. Within MANFRED this data were used to estimate changes of the background concentrations towards the end of this century, upon which we added the fine resolution data as obtained by the interpolation method.

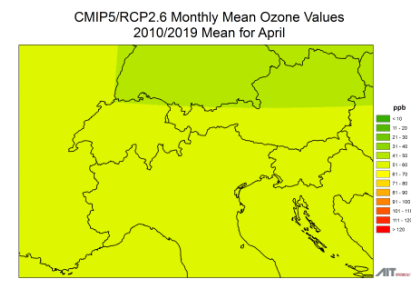

CMIP5/RCP8.5 Monthly Mean Ozone Values

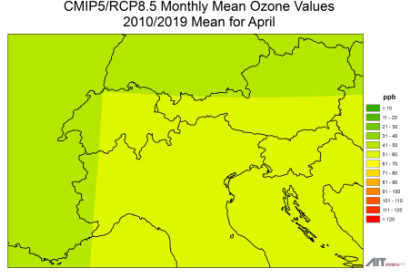

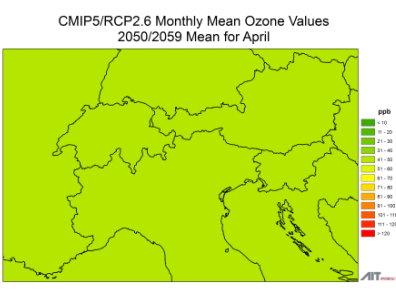

CMIP5/RCP8.5 Monthly Mean Ozone Values

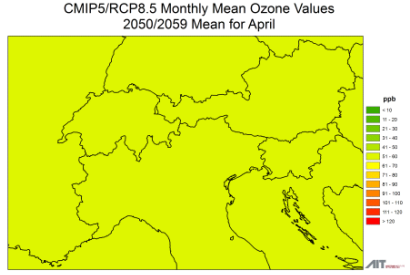

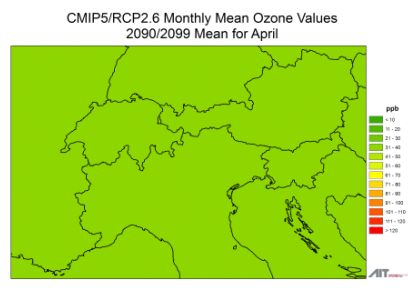

CMIP5/RCP8.5 Monthly Mean Ozone Values

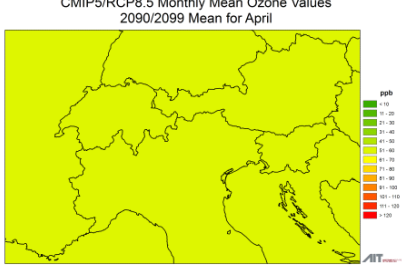

Figure 14. Estimation of future monthly mean ozone concentration - April 10-year means for scenario RCP2.6 (top row) and scenario RCP8.5 (bottom row) for decades 2010/2019, 2050/2059 and 2090/2099 (from left to right)

The change signals found in this dataset (Figure 15 second row) were added to the 5-year means (2003-2007) of monthly mean ozone concentration derived from the 1-hourly interpolated ozone concentration maps (Figure 15 first row). For future scenarios AOT40 maps have been estimated by using the dependencies between monthly mean ozone concentrations and monthly parts of the AOT40 (Figure 15third row). Possible changes of AOT40 values towards the end of the century are shown in the fourth row of Figure 15.

2 The Representative Concentration Pathway or RCP scenarios describe future emission situations at different climate forcing $\left(2.6 \mathrm{~W} / \mathrm{m}^{2}\right.$ and $\left.8.5 \mathrm{~W} / \mathrm{m}^{2}\right)$ in the year 2100 , but encompass air pollutant emissions also.

3 (WCRP's) Coupled Model Intercomparison Project phase 3 (CMIP3) multi-model datasetis made available publicly by the modelling groups, following the RCP scenarios. This data represent monthly mean ozone concentrations on a global scale with a spatial resolution of $5^{\circ}$. The Program for Climate Model Diagnosis and Intercomparison (PCMDI) collects and archives this data, and the WCRP's Working Group on Coupled Modelling (WGCM) organized the model data analysis activity. The WCRP CMIP3 multi-model dataset is supported by the Office of Science, U.S. Department of Energy. 


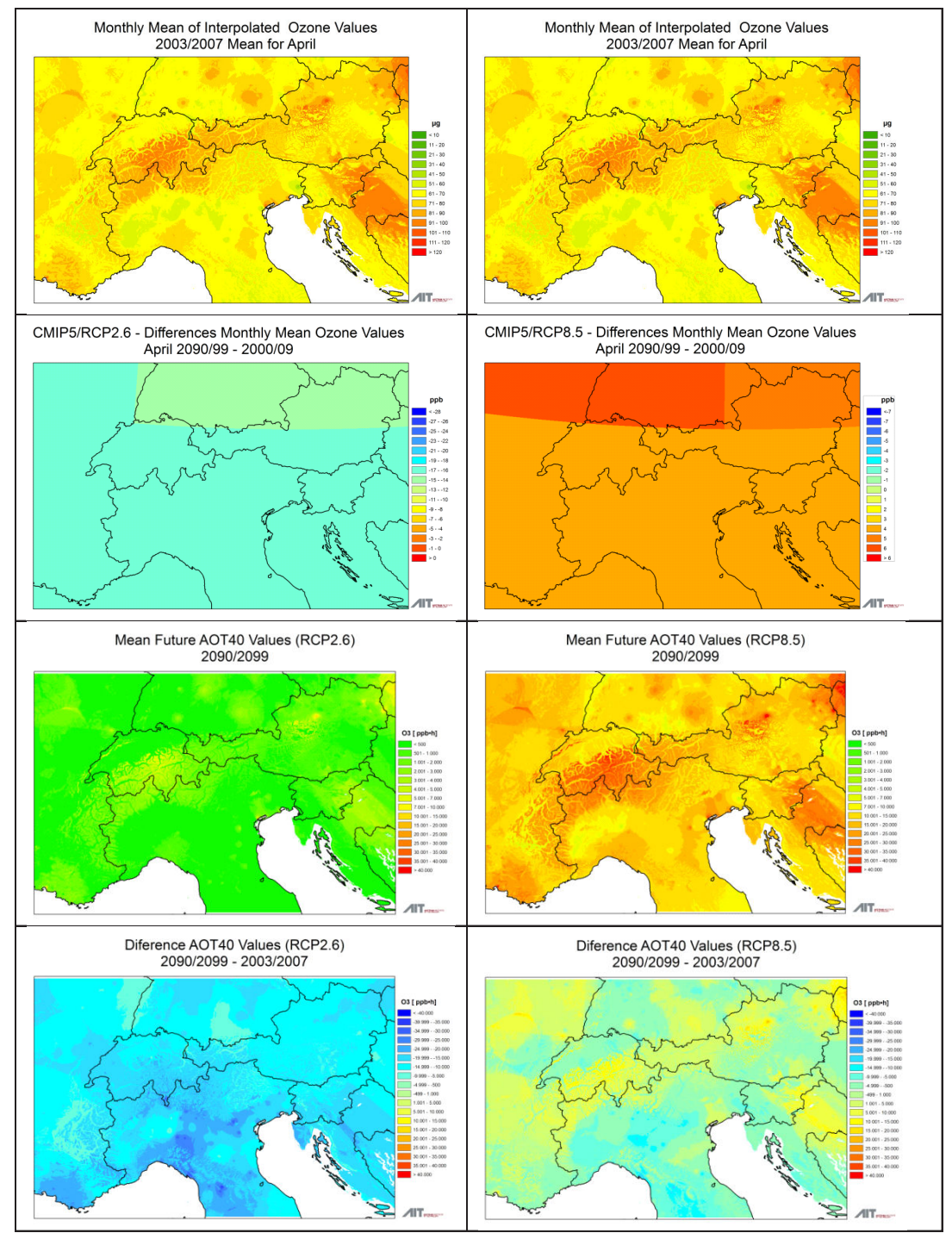

Figure 15. Monthly mean ozone concentrations for April, potential changes in the future, expected values towards the end of 21st century and differences to the period 2003-2007 following scenario RCP2.6 (left) and RCP8.5 (right).

The two RCP scenarios has lead to two significantly different forecasts for ozone risk assessment, mostly due to the characteristics of the scenarios. In fact, The RCP8.5 (the results on the right in Figure 15) can be understood as a scenario that comprises economic growth as well as increased energy demand including associated emission trends. Some technological improve- 
ments on abatement technologies are overcompensated by growth [16]. At least in mountainous regions this scenario reflects an increase compared to current levels of ozone accumulation which result in an increased potential ozone risk for forest. There is an overall increase in a large part of the Alpine region but in particular in the southeast of the Swiss and in the central and west part of Austria. The situation for the RCP2.6 Scenario [17] is in plain contrast. As cobenefits to the reduction in energy consumption needed to achieve the low climate forcing, also pollution is reduced drastically leading to ozone levels clearly below the current adverse conditions. The strong reduction of the pollution levels might lead also the AOT40 to values which might be under current critical level of the AOT40 index.

It is worth noticing that AOT40 represents only a potential risk [9] and that this index does not take into account the plant physiology, so even in a positive situation like RCP2.6, the real situation on field could be different, in fact other climatic results of the project highlighted an increase in summer drought and in autumn and winter precipitation. The combined effect of these two results lead to a decrease of the ozone uptake during the summer, as a consequence of a reduced stomatal activity but also to a possible increase of the ozone uptake in winter. This period is usually not considered in the evaluation of the ozone risk assessment, mainly because the vegetation activity and the ozone concentrations are low, but taking also into account the increase in temperature of all climatic scenarios, the ozone risk during the winter months can significantly increase. Furthermore it should be remarked that the two chosen scenarios represent in one case a very good situation (strong reduction of pollution) and in the other a balanced situation (economic growth taking care of the atmospheric emissions) and no pejorative scenario was considered.

\section{Conclusions}

The ozone risk assessment was evaluated for the first time at the whole Alps scale, realizing AOT40 maps for 5 consecutive years (2003-2007) and averaging them as suggested in [9]. A great interannual variability was observed and a potential higher ozone risk was identified for the southern part of the Alps.

The experimental field campaign run in Valle Camonica and the following analyses lead to develop local scale maps of the ozone risk which were in a substantial good agreement with the one obtained from monitoring stations only. Some differences were observed, especially at high elevations, but this was mostly due to the denser grid of passive sampler measuring point in the valley.

This intercomparison allowed to develop a semi-empirical relationship between monthly AOT40 values and the monthly average concentration. This relationship was used to estimate future AOT40 values, in fact the monthly average concentrations are the only output of chemical composition models. In this way it was possible assess the ozone risk in the period 2090/2099: in the more optimistic scenario, with strong pollution reduction, a substantial decrease of the AOT40 values was observed, which might result lower than the critical level; 
in the other scenario, where economic growth is balanced by more attention to the emissions, a significant increase of the AOT40 in the central Alps is forecast.

\section{Acknowledgements}

This publication was funded by the Catholic University's program for promotion and divulgation of scientific research. The authors thank the Adamello Park and the mountain community of valle Camonica and in particular dr G.B. Sangalli, dr A. Ducoli and for their support in realizing this field campaign. A sincere thank to dr E. Soncina and Federico Fausti for their support in 2010.

\section{Author details}

Angelo Finco ${ }^{1}$, Stefano Oliveri ${ }^{1}$, Giacomo Gerosa ${ }^{1}$, Wilfried Winiwarter ${ }^{2}$, Johann Züger $^{2}$ and Ernst Gebetsroither ${ }^{2}$

1 Catholic University of the Sacred Heart, Mathemathics and Physics Department, Catholic University of the Sacred Heart, Brescia, Italy

2 Austrian Institute of Technology GmbH, Vienna, Austria

\section{References}

[1] Fuhrer, J., Skarby, L., Ashmore, M.R., 1997. Critical levels for ozone effects on vegetation in Europe. Environmental Pollution 97 (1-2), 91-106.

[2] Wustman, B.A.,Oksanen, E., Karnosky, D.F., Noormets, A., Isebrands, J.G., Pregitzer, K.S., Hendrey, G.R., Sober, J., Podila, G.K.. Effects of elevated CO2 and O3 on aspen clones varying in $\mathrm{O} 3$ sensitivity: can $\mathrm{CO} 2$ ameliorate the harmful effects of O3? Environmental pollution $2001 ; 115,473-481$.

[3] Fredericksen, T.S., Joyce, B.J., Skelly, J.M., Steiner, K.C., Kolb, T.E., Kouterick, K.B., Savage, J.E., Snyder, K.R.. Physiology, morphology, and ozone uptake of leaves of black cherry seedlings, saplings, and canopy trees. Environmental Pollution 1995; 89, 273-283.

[4] Lee, J.C., Skelly, J.M., Steiner, K.C., Zhang, J.W., Savage, J.E.. Foliar response of black cherry (Prunusserotina) clones to ambient ozone exposure in central Pennsylvania. Environmental Pollution1999; 105, 325-331. 
[5] Bermejo, V., Gimeno, B. S., Sanz, M. J., De La Torre, D., and Gil, J. M.: Assessment of the ozone sensitivity of 22 native plant species from Mediterranean annual pastures based on visible injury, Atmospheric Environment 2003; 37, 4667-4677.

[6] King, J. S., Kubiske, M. E., Pregitzer, K. S., Hendrey, G. R., Mc Donald, E. P., Giardina, C. P., Quinn, V. S., and Karnosky, D. F.: Tropospheric O3 compromises net primary production in young stands of trembling aspen, paper birch and sugar maple in response to elevated atmospheric CO2. New Phytologist2005; 168, 623-636.

[7] Felzer, B., Kicklighter, D., Melillo, J., Wang, C., Zhuang, Q., and Prinn, R.: Effects of ozone on net primary production and carbon sequestration in the conterminous United States using a biogeochemistry model, Tellus B 2004; 56, 230-248.

[8] Kolb T.E., Matyssek R.. Limitations and perspectives about scaling ozone impacts in trees. Environmental pollution 2001; 115, 373-393.

[9] UN/ECE, Mapping Manual Revision, 2004. UNECE convention on long-range transboundary air pollution. Manual on the Methodologies and Criteria for Modelling and Mapping Critical Loads and Levels and Air Pollution Effects, Risks and Trends. $<$ www.icpmapping.org>.

[10] Loibl, W., Smidt, St.. Potential Ozone Risk for Selected Tree Species in Austria, Environmental Science and Pollution Research1996; 3(4) 213-217.

[11] Loibl, W., Modelling Tropospheric Ozone Distribution considering the spatio-temporal dependencies within complex terrain; in J. Kraak, M. Molenaar (eds.) Advances in GIS ReseachII.Taylor\& Francis Ltd. London. 1997; 667 - 678.

[12] Gerosa, G., Ballarin Denti, A..Regional scale risk assessment of ozone and forests. In: Karnosky D.F., Percy K.E:, Chappelka A.H., Simpson C., Pikkarainen J. (Eds). “Air Pollution, Global Change and Forests in the New Millennium", Elsevier Ltd., 2003 119-139

[13] Gerosa,G.,Finco A.,Marzuoli R.,Ferretti M. and GottardiniE.. Errors in ozone risk assessment using standard conditions for converting ozone concentrations obtained by passive samplers in mountain region. Journal of Environmental Monitoring 2012;14, 1703-1709.

[14] Gerosa, G., Ferretti, M., Bussotti, F. and Rocchini, D.. Estimates of ozone AOT40 from passive sampling in forest sites in South-Western Europe. Environmental Pollution 2007: 145(3), 629-635.

[15] Cionni, I., Eyring, V., Lamarque, J. F., Randel, W. J., Stevenson, D. S., Wu, F., Bodeker, G. E., Shepherd, T. G., Shindell, D. T., and Waugh, D. W.. Ozone database in support of CMIP5 simulations: results and corresponding radiative forcing, Atmospheric Chemistry and Physics 2011 11, 11267-11292. 
[16] Riahi, K., Rao, S., Krey, V., Cho, C., Chirkov, V., Fischer, G., Kindermann, G., Nakicenovic, N., Rafaj, P.,. RCP 8.5-A scenario of comparatively high greenhouse gas emissions. Climatic Change 2011;109, 33-57.

[17] Vuuren, D.P., Stehfest, E., Elzen, M.G.J., Kram, T., Vliet, J., Deetman, S., Isaac, M., Klein Goldewijk, K., Hof, A., Mendoza Beltran, A., Oostenrijk, R., Ruijven, B.,. RCP2.6: exploring the possibility to keep global mean temperature increase below $2^{\circ} \mathrm{C}$. Climatic Change 2011; 109, 95-116. 
